\title{
Editorial
}

\section{Nick Higgs}

Associate, Arup, London, UK

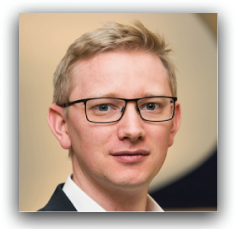

The construction industry has been a relative latecomer to the full benefits of the digital revolution but is now catching up apace. The implementation of building information management (BIM) for design, construction and asset management; the integration of sensors into built infrastructure; the use of drones for remote inspection; the upsurge in off-site manufacture; and the use of large-scale threedimensional printing are all examples where the industry is seeking to benefit from the efficiencies that the increased use of technology can bring. One area that has yet to be impacted is in the decisionmaking processes by which construction projects are initiated. Just as design has the potential to move to a more parametric approach, could greater certainty of outcome be provided by applying a more structured approach to the decisions which influence the procurement of projects?

It is possible to foresee a future in which, based on standard input variables, the procurement route and choice of contract are decisions which will become automated. Contract conditions could be produced at the touch of a button, perhaps in a programming code rather than a natural language; the supply-chain selected automatically based on expertise and appropriateness for the task; pre-orders for materials placed by computer when conditions in the commodities markets are most favourable. Such a future is not inconceivably distant. However, we don't yet have an 'app' for that.

It is trite to say that construction is a special case because of the unique nature of each project, but this is a very real factor which limits the automation of the processes of procurement. In addition, each client has different drivers for success, different past experiences and different advisors each with their own experience and preferences. The inherent uncertainties and, indeed, occasional randomness of decision-making render modelling of the decision-making process more difficult. Modelling is, however, a necessary first step in being able to categorise and analyse the steps in the process and the factors which influence outcomes.

The paper by Martin et al. (2017) seeks to overcome this hurdle by applying cloud theory to the decision model for project delivery selection. The application of cloud theory permits the randomness and uncertainty of decision making to be incorporated into the model. In this very thorough presentation, the authors have identified significant factors influencing decisions and eight suggested delivery models: from traditional procurement to turnkey contracting. Applying the model to a relatively simple case study indicates that the results correlate with real-world experience. This could be a very interesting first step in moving towards more automated, or at least technologyassisted, decision-making for project delivery.

One of the difficulties in replicating human decision-making using computer power is that so much of our reasoning is founded upon our experience and knowledge. Although machine-learning is increasing in capability all of the time, much of construction requires the application of practical skills and experience. Such experience is difficult to reduce to the type of knowledge that can be absorbed by the 'brain' of the latest artificial intelligence incarnation. It is not only difficult to share this knowledge technologically, but even between co-workers, projects and organisations. Knowledge management is a field which seeks to categorise this knowledge and improve its acquisition, exploitation and evaluation. It may seem obvious that improving knowledge management would have a correlation with reducing poor quality (and associated costs) in construction, but this is a topic which has received limited attention to date.

Suresh et al. (2017) address this deficiency by presenting a comprehensive review of the existing knowledge management theory and the potential application to reducing the cost of poor quality in construction. In-depth interviews and questionnaire surveys examined the effectiveness of knowledge management in construction, and the areas in which focused improvements could have the greatest effect. A helpful framework is presented by the authors for categorising this relationship; it should be of use to practitioners seeking to benefit from their research. It is interesting to note that respondents saw the most significant means of knowledge transfer as being through apprenticeships and mentoring. Perhaps there is some knowledge which still requires face-to-face contact and real-world experience to pass on effectively.

In the spirit of improving knowledge sharing, Ashok Ghosh provides a briefing on the recent case of Versloot Dredging in which the UK Supreme Court considered some interesting questions around the content of the utmost good faith obligation in insurance contracts (Ghosh, 2017). Although the question 'When is it OK to lie to your insurer?' would be expected always to be answered with 'Never', 
the case seems to suggest that there may be some very limited circumstances where a relaxation might be permissible. Oluwole Olatunji has also provided a review of Adrian Taggart's book Project Management for Supplier Organisations: Harmonising the Project Owner to Supplier Relationship. Collaboration across the supply chain is an increasing theme of modern construction projects and this book will be a valuable contribution to enabling this change of approach.

Should you have any comments on any of the articles in this edition you would be very welcome to contact the journal by email, or join the conversation online. Do remember that the Institution of Civil Engineers publishes articles ahead of print on its Virtual Library website, enabling you to get the first read of new content.

Finally, the editorial panel is planning three themed issues in the coming months: 'Off-site construction and design for manufacture'; 'Financing of infrastructure projects'; and 'Recent advances in construction technology or management'. Should you have a paper which may be suitable for inclusion please contact Claire Robinson, Journals Editor, at claire.robinson@ icepublishing.com.

\section{REFERENCES}

Ghosh A (2017) Recent developments in construction and engineering insurance law. Proceedings of the Institution of Civil Engineers - Management, Procurement and Law 170(1): 3-5, http://dx.doi. org/10.1680/jmapl.16.00041.

Martin H, Lewis T, Peters E and Petersen A (2017) Construction project delivery cloud decision-support model. Proceedings of the Institution of Civil Engineers - Management, Procurement and Law 170(1): 6-26, http://dx.doi.org/10.1680/jmapl.15.00018.

Suresh S, Olayinka R, Chinyio E and Renukappa S (2017) Impact of knowledge management on construction projects. Proceedings of the Institution of Civil Engineers - Management, Procurement and Law 170(1): 27-43, http://dx.doi.org/10.1680/jmapl.15.00057. 